\title{
COHESION IN THE ABSTRACT OF THE THESES WRITTEN BY UNDERGRADUATE STUDENTS OF ENGLISH EDUCATION PROGRAM
}

\author{
Rahma Dania \\ Universitas Putra Indonesia "YPTK" Padang, Indonesia \\ Email: $\underline{\text { rahmadania.azed@gmail.com }}$ \\ Submitted:04-08-2018 \\ Reviewed:03-09-2018 \\ Accepted:26-09-2018 \\ DOI: $\underline{\text { https://doi.org/10.22202/tus.2018.v4i2.2844 }}$
}

\begin{abstract}
This study aims to explore the use of cohesive devices in the abstracts of the theses written by undergraduate students of English Education Program at a state university in Bandung. This study also attempts to reveal the contributions of the cohesive devices used by the students in their abstract to build the cohesiveness of the text. This study belongs to a descriptive study involving 42 abstracts as the data of the study. This study exposes two main findings. First, cohesive devices that are employed in students' abstract are reference, conjunction, substitution, and lexical cohesion. Second, each device gives significant contribution to the cohesiveness of students' abstract. Reference contributes to keep track of the participants of the text. Meanwhile, the contribution of conjunction in students' abstract is to connect the preceding part with the next one systematically. In addition, substitution is used by the students to avoid repetition in their abstract. Based on these findings, it can be concluded that cohesive devices are important devices to create cohesive abstracts.
\end{abstract}

\section{Keywords: Abstract, Cohesion, Writing}

\section{INTRODUCTION}

Writing is one of the important skills, yet many linguists found that most students considered writing a difficult subject (Emilia, 2005; Ghasemi, 2013). In doing writing, the writer needs time to think, write, edit, and rewrite (Creswell, 2009; Dania, 2012). In tertiary level, students' mastery of writing skill will be tested through academic writing. In the end of their study, students in tertiary level have to perform their writing skill in the form of research paper or thesis. Emilia (2012) states that writing a thesis is difficult. Meanwhile, Brown (2006 as cited in Emilia, 2012) claims that writing a thesis will be more difficult for ESL/ EFL students 
Thesis is an academic writing that should be finished by every student. As the most important requirement, students should be able to write the thesis in good structure. One of the important elements of a thesis is an abstract (Emilia, 2012). The function of the abstract is to give a summary of the thesis to the reader (Thomas, 2000 as cited in Emilia, 2012). In addition, Pearce (2005 as cited in Emilia, 2012) states that an abstract is the most important part of the whole thesis. Since the abstract plays an important role in the thesis, students should be able to write a well-written abstract.

However, a well-written abstract is rather difficult to be written because of three reasons. The first one, an abstract is usually written at the end of the thesis writing process. In relation to this, sometimes the supervisor does not pay attention to the abstract written by the students. The second one, an abstract is a concise summary from the whole thesis. Meanwhile, students need to write every element that should be written in the abstract. However, they have limited space for it. In relation to this, choosing the best sentences to put in the abstract will be difficult. The last one, since the abstract is a summary of the whole thesis, it should cover all parts of the thesis and should be written in limited sentences. Therefore, the abstract must be written as a cohesive text, not just a collection of unrelated sentences. As Emilia (2014, see Normant, 1994; Palmer, 1999; Normant, 2002; Ahmed, 2010; Hameed, 2008; Salmani, 2007; Tangkiengsirisin, 2010; Wahby, 2014) said, a text is cohesive if the whole text has the sentences that are semantically intertwined and consistent. In other words, students need to write a cohesive abstract in order to make readers easily understand the abstract.

Related to the problems aforementioned, this research tries to reveal two major research questions. They are;

1. What types of cohesive devices used by the students in their abstract?

2. How do the cohesive devices contribute to the cohesion of students' abstract?

\section{Text and Texture}

The term text derives from the Latin word means weaving (Emilia, 2014; see also Emilia, 2011). It defines as "words or sentences woven together to create 
a single whole (Cristie and Misson, 1998 in Emilia, 2011: 71). Halliday and Hasan (1976) stated that the word text refers to any passage in linguistics. It can be spoken or written. It is not depend on the length as long as it forms a unified whole.

To Halliday and Hasan (1976), a text is a semantic unit. A unified whole of a text is realized by the meaning of the whole. A text is not defined by its size. "It may be anything from a single proverb to a whole play, from a momentary cry for helping to an all-day discussion on a committee." (Halliday and Hasan, 1976: 1) It can cover both of spoken or written.

A Good text must have texture considering a text which is defines by unity of meaning, not its length as states before. The texture is something to do with "the property that distinguishes text from non-text. Texture is what holds the clauses of a text together to give them unity" (Eggins, 2004: 24). A text must have texture.

To distinguish the difference between a text and non-text, we have to see whether the text has texture or not. The texture is the properties of a text. It can be achieved by cohesion and coherent (Priyatmojo, 2011; Rahayu, et al., 2015; Piriyasilpa, 2009). Coherence includes the text's relationship to its extra-textual context (Eggins, 2004) and cohesion involves the way the elements within a text bind it together as a unified whole. In this way, cohesion includes the use of linguistic resources to combine the text as a whole. Meanwhile, coherence is concerned the meaningful way of how a text unfolds within particular social setting.

\section{Cohesion in Students' Writing}

Cohesion defined as relations of meaning that exist within the text (Halliday and Hasan, 1976). Further, Halliday and Hasan (1976) explain that cohesion exists when the interpretation of some elements in the discourse are dependent while some others are independent. It means that the dependent element presupposes the other element. The dependent element can be decoded effectively when there is an independent element as the presupposed item. For example, "wash and core six 
cooking apples. Put them into a fireproof dish." (Halliday and Hasan, 1976: 2). In this sentence, the word them is a dependent element. It does not have meaning if the first sentence does not exist. It can be concluded that the word them presupposes the phrase six cooking apples in the preceding sentence. As Halliday and Hasan (1976) sum up that the presupposition gives cohesion between the two sentences, so that it can be called as a text.

The concept of cohesion is built through two groups of ties, i.e. grammatical cohesion and lexical cohesion (Halliday and Hasan, 1976). Grammatical cohesion consists of reference, conjunction, substitution and ellipsis. The first cohesion device is reference. Reference means pointing to something in a text. It happens when the same thing come again in the text. It refers to the situation where the identity of an item is retrieved from either within or outside the text (Halliday, 1994; Gerot and Wignell, 1994; Eggins, 2004; Paltridge, 2006). Halliday and Hasan (1976) proposed that reference is a specific nature of information that is signaled for retrieval. It is a semantic relation that creates cohesion by creating links between elements (Halliday and Hasan, 1976: 37; Halliday and Matthiessen, 2004). In other words, reference relates one element of the text to another element of its interpretation in the text. In addition, Halliday and Matthiessen (2004) states that reference is a relationship between things or facts that may be established in varying distance. Moreover, it usually serves to relate single elements that have a function within the clause.

The second one is conjunction. The definition of conjunction is the semantic system where speakers/ writers relate clauses by using conjunctive words (Gerot and Wignell, 1994; Paltridge, 2006). According to Eggins (2004) this cohesive pattern refers to how the writers/ speakers create and express logical relationships between the parts of a text. Further, Eggins (2004) explains that conjunction helps to create semantic unity that characterizes meaningful structures and unproblematic text. In short, conjunction gives relation between parts of the text.

The next one is substitution. Substitution is defined as the replacement of one element in the text by another element (Halliday and Hasan, 1976). Substitution is a term for replacing a component of clause with a shorter word 
such as, one, some, and do (Droga and Humphrey, 2003). Bloor and Bloor (1995) states that substitution occurs when a speaker or writer need to avoid the repetition of a lexical item. It is also able to draw on one of the grammatical resources of the language to replace the item. In line with that, Carter and McCarthy (2006) also said that the substitution is used in order to substitute a word, phrase, or clause instead of repeating them, which occur elsewhere in the text (see also Bloor and Bloor, 2004; Emilia, 2014). In other words, substitution is the replacement of one item by another.

The last one is ellipsis. The cohesiveness of a text could also be seen through the effectiveness of the text. To avoid the repetition of every element of a text, the elements of a clause can be omitted (Droga and Humphrey, 2003). The omission of words, groups or clauses is called ellipsis (Bloor and Bloor, 2004; Emilia, 2014). Halliday and Hasan (1976) explain that ellipsis refers to a presupposed anaphoric item, the substitution by nothing, or the omission of an item. Then, ellipsis operates its items through its structural link, nominal, verbal and causal level. Further, Halliday and Hasan (1976) state that ellipsis deals with something left unsaid. It belongs to something understood or going without saying. In line with that, Akindele (2011) says that ellipsis is the idea of omitting part of sentences on the assumption that an earlier sentence will make the meaning clear. It can be concluded that ellipsis is the omission of a part of a sentence to avoid repetition in the text.

\section{Academic Writing}

Academic writing is the kind of writing used in high school and college classes.The purpose of academic writing is to inform, instruct, enlighten, and to pursuit the reader. It also relies on studies and work published by other scholars (Susana, 2012). Every student who is going to write an academic writing should imagine that their writing will be read by not only supervisors but also examiners and other academic readers.

In tertiary level, the students are required to write an academic writing as requisite to leave the university or college. This kind of academic writing is called 
a thesis and it is considered as elementary level research project (Reardon, 2006). As a research report, a thesis has a systematic structure. Every part of the thesis has its own function. The followings are the structure of the thesis based on Alwasilah (2008) and Emilia (2008): title page, declaration page, approval page, abstract, acknowledgement, table of contents, list of figures and tables, dedication page, introduction, review of the related literature, research methodology, results or findings, discussions, conclusions, bibliography, and appendices. This sequence must be followed by every student systematically.

The abstract is usually written in the end of the writing process but it has an important role in the thesis (Emilia, 2012). The main function of the abstract is to give a summary about the whole thesis to the reader (Thomas, 2000 as cited in Emilia, 2012).In order to fulfill the function, the abstract should provide a brief but complete overview of the thesis to inform the objective, the context, and the findings of the study (Clare and Hamiltom, 2007). A good abstract uses welldeveloped paragraph that is concise and cohesive. It should be able to stand alone as a unit of information and should always be written as clearly understandable texts.

\section{METHODS}

This research employs a qualitative research approach, considering most features of this study embraced qualitative characteristics. The results of this study were elaborated in words and it is suitable with the nature of qualitative research design which concerns words and description rather than numbers. The method employed in this study is descriptive approach. The reason is because the researcher analyzed the data descriptively and the presentation of the result was in a form of explanation of words which would be supported by data presented in the form of tables.

This study was conducted at one state university in Bandung, Indonesia. The population of this study was the abstracts of the theses taken from students of English education program. The source of data in this study were students' abstract of the theses taken from students who are graduated in 2014 and 2015. 
The collection of abstracts of the theses in the chosen academic years is available in repository.upi.edu. In this study, the total population of the research is 95 abstracts written by the students who were graduated from the latest academic years. Meanwhile, the sample of this study was 42 abstracts taken by using random sampling from the total population.

In this study, the information of how cohesion used in the students' abstract was the main idea trying to discover. In order to accomplish the goal, the students' abstract of the theses were investigated and analyzed based on Halliday and Hasan's work of cohesion analysis (1976). The abstracts were also analyzed based on analysis terms of interpretation of the devices by Eggins (2004). Furthermore, the data were analyzed by using the following procedures.

First, read each abstract several times carefully sentence by sentence and numbered each sentence to make the analysis easier. Then, the word or phrase that meets the criteria of cohesive devices on the text was underlined. There were five cohesive devices being analyzed in this study and each of them was marked with certain code. The following table showed the code of each cohesive device found in this study.

Code System for Data Analysis

\begin{tabular}{|c|c|c|c|}
\hline No. & \multicolumn{2}{|c|}{ Cohesive Devices } & Code \\
\hline \multirow[t]{6}{*}{1} & \multirow{6}{*}{ Reference } & Personal & PR \\
\hline & & Reference & \\
\hline & & Demonstrative & DR \\
\hline & & Reference & \\
\hline & & Comparative & CR \\
\hline & & Reference & \\
\hline 2 & \multicolumn{2}{|c|}{ Substitution } & $\mathbf{S}$ \\
\hline 3 & \multicolumn{2}{|c|}{ Conjunction } & $\mathrm{CON}$ \\
\hline 4 & \multicolumn{2}{|c|}{ Ellipsis } & $\varnothing$ \\
\hline 5 & \multicolumn{2}{|c|}{ Lexical Cohesion } & $\mathbf{L C}$ \\
\hline
\end{tabular}


Based on the table 3.1 above, reference is divided into three categories namely personal reference, demonstrative reference, and comparative reference. Each category was marked with the code PR, DR, and CR. Then, substitution found in the analysis was marked with the code $\mathbf{S}$. Next, conjunction was labeled with the code CON. Ellipsis was marked with symbol $\varnothing$. Afterwards, lexical cohesion was labeled with the code $\mathbf{L C}$.

The next step in data analysis was listing. The words which represent each of cohesive devices were listed in the table consists of sentence number, total of cohesive devices found in each sentence, the words represent the devices, type of cohesive devices as well as the categories, and presupposed item.

The last step was recapitulating the results of data of each text. Total of reference, substitution, conjunction, ellipsis, and lexical cohesion found in the text were recapitulated in the listing table.

\section{FINDING AND DISCUSSION}

\section{a. Realizations of Cohesive Devices in Students' Abstract}

This study analyzed 42 students' abstracts. From 42 abstracts, it was found that there were four types of cohesive devices used by the students in their abstracts. The cohesive devices identified in students' abstract can be classified into four cohesive devices, as mention above. They are reference, substitution, ellipsis, and conjunction.

The following table illustrates overall occurrences of cohesive devices in 42 students' abstract. The table shows that, cohesive devices appeared 1590 times. In particular, the most occurring device is reference, which appeared 1156 times. It is followed by conjunction afterwards with 395 appearances. Then lexical cohesion subsequently followed with 37 occurrences and substitution with 2 appearances. 


\section{Total Occurrences of Cohesive Devices}

\begin{tabular}{cc}
\hline Cohesive Devices & Total Occurrences \\
\hline Reference & 1156 \\
\hline Substitution & 2 \\
\hline Ellipsis & - \\
\hline Conjunction & 395 \\
\hline Lexical Cohesion & 37 \\
\hline \hline Total & 1590 \\
\hline
\end{tabular}

From the table above, it is inferred that students mostly used reference items to develop text's cohesion. It is assumed that reference item is mostly recognizable or needed by students. In the opposite side, there is no student applied elliptical tie to develop text's cohesion.

The illustration about how the analysis was conducted is provided through the following example. This example shows detailed identification of cohesive item in each sentence of the text. In this example, reference is divided into three categories namely personal reference, demonstrative reference, and comparative reference. Each category is marked with the code PR, DR, and CR. Then, substitution found in the analysis is marked with the code $\mathbf{S}$. Next, conjunction is labeled with the code CON. Ellipsis is marked with symbol Ø. Afterwards, lexical cohesion is labeled with the code $\mathbf{L C}$.

\section{Text:}

1. This study focused on analyzing the translation strategies used by the students in translating a political speech of BRarack Obama, the difficulties faced by them in translating it and the quality of the translation works.
PR
PR CON DR DR

2. This study used PR Cescriptive-qualitative method with document analysis technique, using the theory of translation strategy proposed by Vinay \& DR

Darbelnet (in Fawcett, 1997, pp. 34- 9; in Bell, 1991, pp. 70-71) and Newmark (1988).

CON

3. This study also used the NAATI's assessment method to find out the quality Of students' translation Works. 
4. The main data of this study were the students' translation work of translation DR Students in 8th semester.

5. The findings showed that the students employ nine translating strategies in DR ing with the text DR DR

dealing with the text, there were transposition $(49,33 \%)$, reduction $(14,66)$,

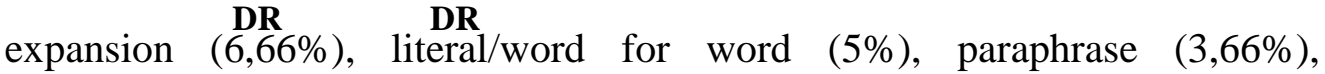
naturalization $(3,33 \%)$, equivalence $(3 \%)$, couplets $(2,66 \%)$, and calque $(1,33 \%)$.

6. However it was also found some cases mistranslation which reached $10,33 \%$. CON PR

7. While in terms of difficulties faced by the students in translating a text, it was done by examining vocabulary problem, lexical problem, and syntactic problem.

$$
\text { CON }
$$

8. In terms of students' translation quality, it was found that two of three Participants were judged as acceptable translation while the other one was unacceptable.
DR CR $S$.

9. It can be concluded that the students employ several strategies in translating a $\overrightarrow{\mathbf{P R}}$

political speech and the problem faced by them was complicated since political

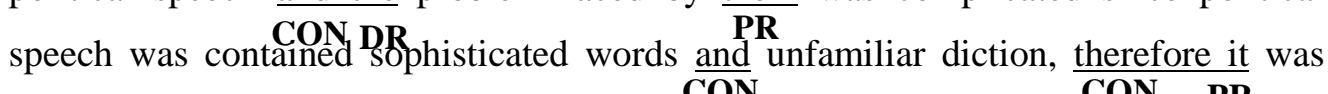
affecting the quality of the translation works. CON
DR
DR

In the example above, the references are represented through personal reference it, them, demonstrative reference this, the, that, there, and comparative reference other. Personal reference it which occurred in sentence 6, 7, 8, and 9 refer to this study. Meanwhile, demonstrative reference this in sentence 1, 2, 3, 4 refer to the study, although the referent is not explicitly stated, it is believed that the readers know about to whom demonstrative reference this refers to. All of the references in this text contribute to keeping the track of the participant of the text.

The substitution presents through words, such as one, ones, the same, so, do, be, have, do the same, likewise, do so, be so, do it, do that, be it, be that, and so, not. In the text above, there is one substitution found in the text. It is represented through the use of word one in sentence \#8. Theoretically, substitution is divided into three types, namely nominal substitutes, verbal substitutes, and clausal substitutes. The word one is included in the first type of substitution which is nominal substitution. Nominal substitution is always 
functioning as head of nominal group and it can only substitute for an item which functions as head of nominal group. In this text, the word one presupposes the word participant in the preceding sentence. Under the circumstance, the contribution of substitution in the text is to replace one item with another.

The next cohesive device found in the text is conjunction. This study uses Halliday and Matthiessen (2004) theory of conjunction. In consequence, there are three types of conjunctions which are analyzed in this study, namely elaborating conjunction, extending conjunction, and enhancing conjunction. In the text above, the writer of the abstract uses two kinds of conjunction which are extending conjunction and enhancing conjunction. The use of extending conjunction is represented in the words and and however in sentence \#1, \#2, \#5, \#6, \#7. Both of these words have different categories of extending conjunction, namely additive and adversative. Then, the use of enhancing conjunction is employed by the word therefore in sentence \#9. The category of enhancing conjunction which employs the word therefore is causal-conditional. Despite the different types and categories of conjunction, this cohesive device is used to connect the preceding sentence with another sentence.

Regarding the elliptical ties, there is no ellipsis in the text because the text does not have missing words. Halliday and Matthiessen (2004) said that missing words in ellipsis must be grammatically appropriate and they can be inserted in place. This cohesive tie is used to refer to a different thing, not refer to the same thing as reference does. In line with the fact that most abstracts are written in a short paragraph but they must summarize the whole thesis, it can be assumed that the use of ellipsis in students' abstract is not necessary.

The occurrences of cohesive devices in the text above are showed in following table. The table presents the elaboration of each cohesive device found in each sentence of the preceding text. 
The Occurrences of Cohesive Devices in Text

\begin{tabular}{|c|c|c|c|}
\hline $\begin{array}{l}\text { Sentence } \\
\text { Number }\end{array}$ & $\begin{array}{c}\text { No. of } \\
\text { Ties }\end{array}$ & $\begin{array}{l}\text { Cohesive } \\
\text { Item }\end{array}$ & Type \\
\hline \multirow{9}{*}{1} & \multirow{9}{*}{9} & This & DR \\
\hline & & The & DR \\
\hline & & The & DR \\
\hline & & The & DR \\
\hline & & Them & PR \\
\hline & & It & PR \\
\hline & & And & $\mathrm{C}$ (Extending) \\
\hline & & The & DR \\
\hline & & The & DR \\
\hline \multirow{3}{*}{2} & \multirow{3}{*}{3} & This & DR \\
\hline & & The & DR \\
\hline & & And & $\mathrm{C}$ (Extending) \\
\hline \multirow{3}{*}{3} & \multirow{3}{*}{3} & This & DR \\
\hline & & The & DR \\
\hline & & The & DR \\
\hline \multirow{2}{*}{4} & \multirow{2}{*}{2} & The & DR \\
\hline & & This & DR \\
\hline \multirow{6}{*}{5} & \multirow{6}{*}{6} & The & DR \\
\hline & & That & DR \\
\hline & & The & DR \\
\hline & & The & DR \\
\hline & & There & DR \\
\hline & & And & $\mathrm{C}$ (Extending) \\
\hline \multirow{2}{*}{6} & \multirow{2}{*}{2} & However & $\mathrm{C}$ (Extending) \\
\hline & & It & $\mathrm{PR}$ \\
\hline \multirow{3}{*}{7} & \multirow{3}{*}{3} & The & PR \\
\hline & & It & $\mathrm{PR}$ \\
\hline & & And & C (Extending) \\
\hline 8 & - & & \\
\hline \multirow{9}{*}{9} & \multirow{9}{*}{11} & It & \\
\hline & & That & \\
\hline & & The & \\
\hline & & And & \\
\hline & & The & \\
\hline & & Them & \\
\hline & & And & \\
\hline & & Therefore & \\
\hline & & It & \\
\hline
\end{tabular}




\begin{tabular}{cc}
\hline & The \\
\cline { 2 - 2 } & The \\
\hline
\end{tabular}

The table shows that almost every sentence of text has some cohesive devices. There are 9 sentences that have been analyzed in the table above. Each sentence used varied cohesive devices. For instance, first sentence used 9 cohesive item namely demonstrative reference, personal reference and conjunction which belong to extending conjunction. Second sentence only used three cohesive items which are two demonstrative references and one conjunction. The writer of the text did not use cohesive item in sentence number eight.

\section{b. The Contribution of Cohesive Ties to Students' Abstract}

This section covers the analysis on the contributions of cohesive devices students used in their abstracts. The analysis is meant to examine the significance contributions of every device found in students' abstracts. From the data analysis, reference has the highest contribution to the cohesiveness of students' abstracts, followed by conjunction, and substitution. The contributions are concluded in three points.

The first contribution is keeping track of the participant. This contribution of cohesive ties is established through reference. This contribution of reference is proposed by Eggins (2004) who said that using cohesive device reference in the text is the way the writer introduces participants and then keep track of them as long as they are mentioned in the text.

The example below will exemplify the use of reference as a mean for introducing the participant. In the excerpt below, it is identified that reference item those refers to criteria of the book that has been mentioned earlier.

Interviews also conducted to find out students' and teacher's opinion towards the books. The result of the study revealed that the books have accomplished 17 criteria out of 19 criteria provided. Those are covers, colors, size, weight, general layout, activities involving movements, activities involving senses, plenty of objects, playing with language though rhymes, songs,... 
The second contribution of cohesive ties is organizing the ideas in logical order. In organizing the ideas, conjunction as the second mostly used cohesive device helps students to arrange the ideas of their abstracts in logical order. The realizations of conjunction employed in the students' abstracts contribute to the cohesion of their abstracts. This cohesive device occurred in all of students' abstracts and is used more than once in an abstract.

The contribution of conjunction toward the cohesion of the text is exemplified in the following example.

By employing a narrative approach in a qualitative method which focuses on the analysis of the main character, Kafka Tamura, and his quest of identity, the findings reveal three main points. First, through the implicit characterization depicted in his preferences, Kafka is portrayed as a teenager who distances himself from the society. Second, the most prominent issue in Kafka's quest of identity is triggered by father-centered conflicts. Third, sex and death in this novel are used as the conflicts resolution. From the analysis, it can be concluded that the identity constructed by Kafka in the end of the novel is a compromised identity who learns to accept the norms and values of the society he intends to leave.

In the text above, the occurrences of enhancement are indicated by first, second, and third as the manifestations of continuity or sequential. In the excerpt above, the conjunction item the findings reveal three main points indicates the calls for a list of arguments. Then, the conjunction item the findings reveal three main points is followed by several arguments in the next sentences. The arguments are discussed one by one through the use of listing conjunction items such as first, second, and third.

In this context, the continuity or sequential relations i.e. first, second, and third refer to logical conjunctions which are categorized as additive-enhancement conjunctions which have the contribution to add the logical information concerning the three findings. Hence, the occurrence of those conjunctions connects the preceding statement the findings reveal three main points. Furthermore, the writer intends to inform the readers concerning the logical reasons which are tied to each other. 
The last contribution of cohesive ties is to avoid repetition and text redundancy. Substitution is a cohesive tool used to avoid repetition and text redundancy. The use of substitution which is applied by the students to substitute one item by another in order to avoid the repetition also gives significant contribution.

The example below shows the contribution of substitution in avoiding repetition and text redundancy.

While in terms of difficulties faced by the students in translating a text, it was done by examining vocabulary problem, lexical problem, and syntactic problem. In terms of students' translation quality, it was found that two of three Participants were judged as acceptable translation while the other one was unacceptable. It can be concluded that the students employ several strategies in translating a political speech and the problem faced by them was complicated since political speech was contained sophisticated words and unfamiliar diction, therefore it was affecting the quality of the translation works.

Substitution in the text above is indicated by the use of the word one. The word one refers to participants in the preceding sentence. It implies that the third participant was judged as unacceptable translation. Furthermore, the writer tries to avoid repetition by substituting one item by another. And, it is also crucial to make the text more efficient as a whole.

\section{Conclusions}

The major conclusions from the analysis of cohesion in students' abstracts of the thesis are taken from the data analysis. First of all, the result of the study revealed that there are only three cohesive devices used by the students in their abstracts, which are reference, conjunction, and substitution. There was no elliptical cohesion or ellipsis found in students' abstracts. Reference as the first device is the most frequently used device in the 42 abstracts. It is continued by the occurrence of conjunction, and the last is the appearance of substitution.

Then, in term of the contribution of cohesive devices in students' abstracts, each of devices gives contribution to the cohesiveness of the abstracts. Reference is used to keep track of the participants that had been introduced earlier in the text. Regarding conjunction contributes to the cohesiveness of students' 
abstracts in connecting the preceding part of the abstract with the next part systematically. Meanwhile, substitution contributes to the process of substituting of one item by another.

\section{References}

Alwasilah, A. C. (2008). Pokoknya Menulis. Bandung: PT Kiblat Buku Utama.

Bloor, T. and Bloor, M. (1995). Functional analysis of English. London: Edward Arnold.

Bloor, T. and Bloor, M. (2004). The functional analysis of English. London: Edward Arnold.

Carter, R. and McCarthy, M. (2006). Cambridge grammar of English: a comprehensive guide spoken and written English grammar and usage. Cambridge: Cambridge University Press.

Creswell, J. W. (2014). Research design: qualitative,quantitative, and mixed methods approaches ( $4^{\text {th }} E d$.). Los Angeles: Sage Publication.

Dania, R. (2012). Teaching Writing a Discussion Text to Senior High School Students by Using Take a Stand Activity. Unpublished research paper. Padang: UniversitasNegeri Padang.

Derewianka, B. \& Jones, P. (2012). Teaching language in context. Melbourne: Oxford University Press.

Eggins, S. (2004). An Introduction to Systemic Functional Linguistics $2^{\text {nd }}$ ed. New York: Continuum.

Emilia, E. (2005). A Critical Genre-based Approach to Teaching Academic Writing in A Tertiary EFL Context in Indonesia. Doctoral Dissertation in Faculty of Education the University of Melbourne

Emilia, E. (2011). Pendekatan genre-based dalam pengajaran bahasa Inggris: Petunjuk untuk guru. Bandung: Rizqi Press

Emilia, E. (2010). Teaching writing: Developing critical learners. Bandung: Rizki Press.

Emilia, E. (2012). Menulis thesis dandisertasi. Bandung: CV. Alfabeta

Emilia, E. (2014). Introducing Functional Grammar. Bandung: Pustaka Jaya. 
Gerot, L. \&Wignell, P. (1994). Making Sense of Functional Grammar. Cammeray: GerdStabler.

Ghasemi, M. (2013). An investigation into the use of cohesive devices in second language writings. Theory and practice in language studies. 3 (9). 16151623

Grabe, W. \& Kaplan, R. B. (1996). Theory and Practice of Writing: An Applied linguistics Perspective. Essex: Longman.

Halliday, M. A. K. \& Hasan, R. (1976). Cohesion in English. London: Longman.

Halliday, M. A. K. and Matthiessen, C. (2004). An Introduction to Functional Grammar. $3^{\text {rd }}$, revised edition. London, England: Edward Arnold.

Knapp, P. \& Watkins, M. (2005). Genre, Text, Grammar: Technologies for Teaching and Assessing Writing. New South Wales: University of New South Wales Press.

Paltridge, B. (2006). Discourse Analysis: an introduction. London and New York: Continuum.

Piriyasilpa, Y. (2009). Periodicity and its use in language teaching. TESL-EJ. 12 (4). Retrieved October $24^{\text {th }}, 2015$ from www.cc.kyoto-su.ac.jp

Priyatmojo, A. S. (2011). Cohesion and coherence of the students texts and its implication for teaching writing of text types in English. Retrieved October $24^{\text {th }}, 2015$, from https://arisuryo.wordpress.com

Rahayu, T., Cahyono, B. Y. (2015). Discourse markers in expository essays written by Indonesian students of EFL. International journal of language and linguistics. 2(2). 21-29 